\title{
High Power Laser Weapons and Operational Implications
}

\author{
Nelson Alex Roso', Romero da Costa Moreira1, José Edimar Barbosa Oliveira1
}

\begin{abstract}
The operational implications of high power laser weapons are constantly growing in countries with advanced military technological level. As well as on progress in integration with air, land and naval platforms, this paper discusses the necessary development and implementation of the operational concepts into Armed Forces, which should target orientation in the improvement process of the appropriate warfare material, i.e. the laser, as well as remodeling the existing combat's doctrine. Finally, we highlight some capabilities and limitations inherent in the technology of lasers and present some applications in defense and attack operations enabled by the implementation of laser weapons.
\end{abstract}

KEYWORDS: Weapons systems, Laser, Operational applications, Photonics.

\section{INTRODUCTION}

The experimental demonstration of the first laser was performed by Theodore Maiman on May 16, 1960, and preceded numerous scientific and technological areas, which have provided great advances in telecommunications, instrumentation and armaments industries, among others (Hecht, 2010).

In Brazil, it is noteworthy that the formation of human resources and the development of research on laser within the Departamento de Ciência e Tecnologia Aeroespacial (DCTA) former Centro Tecnológico da Aeroespacial (CTA), are performed by the Instituto Tecnológico de Aeronáutica (ITA) and the Instituto de Estudos Avançados (IEAV) for over thirty years. In these institutes, significant results have been obtained in the areas of high power laser (HPL), optical sensors and communications links with optical fiber, among others (Monteiro et al., 1994).

History reveals that, in areas of defense interest, conventional weapons have dominated warfare for centuries. Nowadays, the primacy of cartridge is replacing the projectiles for HPL, as technological advances in photonics introduce systems capable of destroying materials hardness, as well as protecting centers of Command and Control with early warning systems integrating lasers. Projectiles, e.g., mortars and missiles, are passive of interception and destruction by lasers that concentrate large amounts of electromagnetic energy (EME) in very small areas, destroying control systems of guided weapons or causing previous detonation.

The coexistence of conventional weapons systems and concentrated EME weapons is not nearly over, since these complement one another. Emerging possibilities of available technological resources require the fighters, scientists and commanders to have a comprehension of their implications,

\footnotetext{
E 1. Instituto Tecnológico de Aeronáutica - São José dos Campos/SP - Brazil

Author for correspondence: Nelson Alex Roso | Instituto Tecnológico de Aeronáutica | Praça Marechal Eduardo Gomes 50 , São José dos Campos / SP CEP: 12.228-901 - Brazil | Email: nelsonalexroso@gmail.com

Received: 10/03/2013 | Accepted: 06/29/2014
} 
since the war is won with the best job proficiency, e.g., the troops with greater efficiency will dictate the asymmetry of the conflict.

Within the Brazilian Air Force (FAB), the thematic "laser weapons" has received attention as reveal issues on the Air General Commander (COMGAR) Spectrum Magazine, published in 2000, 2001 and 2012.

This paper proves the success of graduate programs and research in the area of defense, provided by FAB for over ten years, making insight into operational implications of laser weapons. Initially, the growing capacity in developing these types of weapons, as well as progress in integration with air, land and naval platforms, is discussed. The need to develop operational concepts into the Armed Forces is also highlighted, mainly to guide the development of laser weapons; as well as a parallel is made between the capabilities and limitations of such weaponry. In addition to that, an approach of attack and defense enabled by the use of laser weapons is made; and finally, a retrospective completion of the main elements addressed is presented.

\section{DEVELOPMENT AND INTEGRATION OF HIGH POWER LASER WEAPONS}

Laser weapons are being created and tested throughout the world, specially in Armed Forces with notable weapons capabilities such as the United States, China, France and Russia, among others. The current example is the Tactical High Energy Laser (THEL), developed for use by the U.S. Army against tactical missiles with short and medium range, as well as the Anti-missile Airborne Laser (ABL) platform used by Boeing 747 U.S. Air Force (USAF) against intercontinental ballistic missiles (Dunn, 2005).

The major challenge in understanding the operational implications of the progress on laser weapons technology is the great variety of characteristics of such weaponry. Technologically, the type of laser that has been developed for military purposes was the chemical type employed in the THEL and ABL, which produces an intense beam of infrared radiation from chemical reactions between its solutes. Also, the solid state lasers (SSL), electrically energized, are less potent, and they depend on crystals which are responsible for originating their beams, but continue in constant evaluation, promising great benefits in light weapons used in the front battle. In a statement, the
Department of Defense of the U.S. (DoD), through the high power solid-state laser development program - announced in December 2004 - had already reached a $25 \mathrm{~kW}$ of power with SSL in the laboratory, although, according to the DoD, it is way far from the power required to be tactically effective, which should be greater than $100 \mathrm{~kW}$ (Dunn, 2005). The system's weight is also a problem, since it has been estimated at about $11,000 \mathrm{Kg}$ for a laser of $100 \mathrm{~kW}$. On the other hand, the American defense industry estimates that the technological development of SSL can reduce this weight to less than 4,000 Kg (Dunn, 2005), allowing the use of lighter and more agile platforms. However, power level is not the only feature to improve. An effective laser gun system must be created, a strong integration between subsystems for acquiring and tracking targets must be made, as well as the system base should monitor and provide enough energy power in several engagements at combat.

Another type of laser with potential applicability in weapons systems is the Free Electron Laser (FEL), whose base of operation is in free motion of a relativistic electron beam through a fixed magnetic structure (Federation of American Scientists, 2013). This type of laser has larger area than others and can be easily tuned to a specific wavelength bandwidth. The FEL technology is being evaluated by the U.S. Navy (U.S.N.) as a good candidate in the introduction of direct energy weapons against missiles and aircrafts. Significant progress has been achieved in increasing the power level of the FEL, and it is possible to consider, in the near future, the construction of compact weapons with this type of laser with megawatt's power. Recently, the North American Thomas Jefferson National Accelerator Facility (2013) — Jefferson Lab - showed that it has reached the power of $14 \mathrm{~kW}$. With emphasis on this expectation, on June 9, 2009, the office of the Research Department of the U.S.N., responsible for promoting science and technology programs of the U.S.N. and U.S. Marine Corps, announced the contract closing with Raytheon Company, for the development of an experimental 100 kW FEL (Popular Mechanics Journal, 2009).

Researchers have also been made to improve the quality of the laser beam at high powers. The laser's feature called Beam Quality (BQ) essentially measures the scattering cross section of the laser beam at a given distance, measuring the ability to focus the laser on the target to form a point of intense light from the platform which employ its. In many cases, the intensity of the focused spot is proportional to $1 / \mathrm{BQ}^{2}$, where $\mathrm{BQ}$ equals 1 , meaning a perfect focus. Therefore, a small increase in 
BQ could result in a decrease of the intensity of the laser energy deposited on the target. Hence, the maintenance of a near BQ equals 1 is a very important requirement in the development of the laser system.

The integration of HPL on air, land and naval platforms must progress in order to suit the needs of the missions focus. As mentioned before, the ABL suited to the B-747 USAF platform, to execute strategic missions, was necessary multiple structural changes on the aircraft in order not to lose the features of the platform performance. Another example of adaptation was the modification on THEL, towards implementing it as a fighting system known as High Energy Laser Rockets and Mortars Artilhary (HELRAM), which may be used to destroy multiple types of threats, including artillery rockets and light mortars (Dunn, 2005).

Several other concepts using the laser from military platforms have been developed, but the limitations in space and weight still remain. Unmanned Aerial Vehicles (UAV), bombers, fighters, ships, submarines, satellites, tanks and many other weapon system platforms may involve HPL, serving as offensive and defensive weapons in the Operation Theatre (OT).

\section{OPERATIONAL CONCEPT BASED ON CAPABILITIES AND LIMITATIONS}

It is necessary that the Armed Forces inform the defense industry theirs requirements, in order to provide the best performance possible. The investment at HPL technologies must be made in order to promote research's development in technology institutes, as well as justifying budget on National Security. At FAB, according Oliveira (2002), the Operational Applications Postgraduate Program (PPGAO), that commissioned militaries from the Air Force, the Navy and the Army, develops operational research on these technological innovations, integrating operational and scientific communities, in order to clarify doubts and to maximize the conceptual and operational outcomes.

Acting as Electronic Protective Measures (Brasil, 2006), selfdefense systems such as the Direct Infrared Countermeasure System (DIRCM) (Northrop Grumman, 2013), are capable to divert the spotlight of laser-guided missiles, confusing their trajectories.

Acting as Electronic Attack Measure (Brasil, 2006), lasers can be used in conjunction with weapon systems of AF to appoint or engage multiple targets, increasing the offensive capability. This function is extremely desirable against fast maneuverable targets such as $\mathrm{UAV}$, surface-to-air missiles (SAM), air-to-air missiles (AAM), rockets and mortars. Notwithstanding this, the currently laser designation, carried out in the FAB by Litening System (Fig. 1), enables the use of "dumb bombs" (with Lizard control kit) with a high degree of accuracy (Northrop Grumman, 2013).

Compatible Energy consumption is proportional to the consumption of chemical fuel (COIL - Chemical Oxygen Iodine) or electricity (SSL) of the system, according to the type of laser. This is a tactical advantage, since the production of electric power at aircrafts, tanks and warships is constant, then the systems will be limited to components heating. The chemical lasers, for example, can operate according to the autonomy of its chemical cartridges, as is the case of HELRAM, which can be used between 10 and 20 times without being refilled, and furthermore, it is possible to operate with serials cartridges such as USAF B-747 ABL, improving the reload speed. In the SSL lasers, the number of shots is limited by the dissipate heat ability and batteries capacity on board. This limitation is called Duty Cycle Limit (Dunn, 2005).

The HPL has low cost per shot, improving the military availability and replacement when compared to guided missiles, that are expensive to manufacture because of the embedded technology involved (rocket motors, guidance systems, avionics, seekers and others).

The HPL has a cost directly proportional to the used energy, which can be produced without additional costs. For instance, the GBU-31 Joint Direct Attack Munition (JDAM) costs around U\$25,000.00, one AGM-154C Joint Standoff

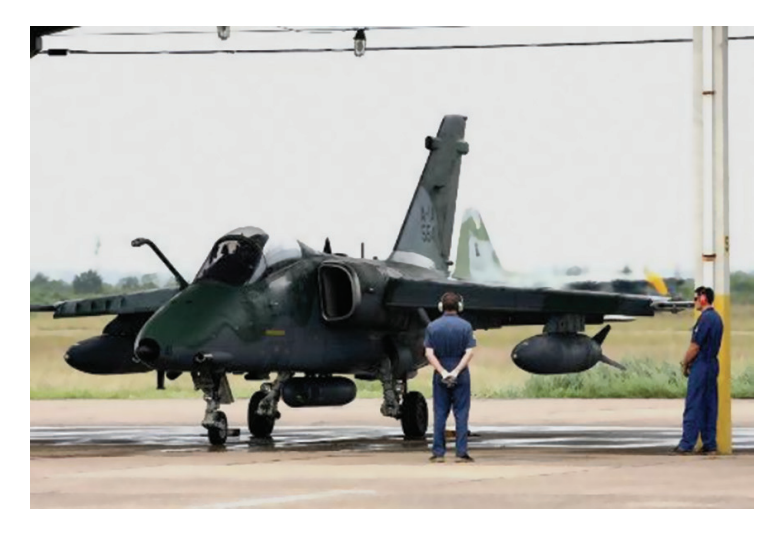

Figure 1. Litening Pod Designator of FAB AMX aircraft (adapted from aereo.jor.br, 2009). 
Weapon (JSOW) costs around U\$720,000.00, one AGM-158 Joint Air-to-Surface Standoff Missile (JASSM) approximately U\$700,000.00, one AIM-120 Advanced Medium Range Air-toAir Missile (AMRAAM) is estimated at around U\$320,000.00 and the AGM-65 Maverick may reach the value of U\$158,000.00 (depending on the variation) (Federation of American Scientists, 2013). In contrast to the values of the weapons above, the cost of the chemical fuel by shot in B-747 ABL, which uses the COIL as laser fuel, is around U\$10,000.00 (Dunn, 2005), indicating operational feasibility of this weaponry.

The accuracy of these systems allows the operator to choose the impact place of the laser beam on the target and to adjust it according to the desired level of damage. This adjustment may be inserted in the beam Dwell Time, setting the duration of laser illumination, reducing the collateral damage.

The combat logistics for the maintenance of HPL is reduced in comparison with conventional systems. For example, guns and launchers need to be reloaded with projectiles and missiles after the shot, while laser weapons need only chemical fuel or electricity to generate energy for their systems.

The ability to adapt to several types of missions, controlling the Dwell Time of the laser beam, makes the HPL weapon platforms a Multi mission crafts, reaffirming the Air Force flexibility feature. However, the technical limitations of laser systems must also be understood by the operational community, some of them are listed below:

- Turbulence and atmospheric attenuation are factors that can affect the propagation of the laser beam, since dust particles, aerosols, water vapor and atmospheric instability lines, absorbing or scattering the laser energy, reducing operational range of application;

- Dependence of line-of-sight with targets, because the laser beam does not make ballistic trajectories;

- Due to the high concentration of energy in a point with a relatively small cross section, the lasers beams are more adjusted for engaging targets with small areas. For example, against combat vehicles, the laser will be effective in components such as antennas, control surfaces, sensors and fuel tanks;

- While chemical lasers generate wavelengths beams which are safe for human vision, the SSL are dangerous regarding these wavelengths. In case of HPL use against a target that does not fully absorb the energy issued, the spread energy by reflection can blind or damage the allied troops at OT if they are not properly protected.
Once the capabilities and limitations are known, the consequences of HPL weapons should be properly discussed.

\section{OPERATIONAL IMPLICATIONS}

The approach of operational implications in the use of HPL weapons does not underestimate the complex doctrinal study for development of military tactics and strategies, therefore, a synthetic implication in offensive and defensive operations on the ground, water, air and space OT's will be explored.

\section{OFFENSIVE OPERATIONS}

Offensive operations using HPL should consider that features of laser itself, such as accuracy, speed and the number of engagements, will be more important than destruction power itself. For example, the same laser that provides an active defense for an aircraft can be used against ground targets, providing a significant air-to-ground capability. Combining these capabilities with new aerial platforms and new sensors, it is possible to increase its potential use, increasing the airpower effectiveness in counterinsurgency and counterterrorism missions, as was done in Pakistan by the USAF. Moreover, the reduction of collateral damage is remarkable, because damage may decrease from many meters to some centimeters.

Strategic air targets such as radio, television and satellite antennas, power transformers, refrigeration and heating systems, which depend on these sites, may be blocked without complete destruction. It is also possible to assume that the SSL development, will change a lot of conventional weapons loaded in modern attack aircraft by HPL systems, which are capable of being used hundreds of times, setting a new limit on station combat, i.e., the human limit and the electromechanical system limits of air platforms. At this point it is possible to foresee the efficient union of SSL lasers and combat UAV.

On surface warfare context, the offensive ground operations should use the HPL weapons on precision missions that require high speed on engagement, adjustability and minimal collateral damage, such as missions against snipers. Laser weapons can be associated with optical and acoustic sensors to locate and to neutralize the sniper instantly, before they perform a shooting. Lasers do not have time of flight compared to the missiles and conventional weapons. However, the stealth features of lasers 
are also used in benefit of sniper weapons, since they are only visible through target damage.

The same limiting factors of laser weapons in ground operations will also limit the naval operations. A good example for the use of these weapons is the integrated laser on submarine periscope, which may engage surface targets such as ships, boats and aircrafts flying at low altitude with greater precision and less collateral damage, not revealing their positions when launching missiles and torpedoes.

In addition to conventional air, land and sea scenarios, there is also the space OT, a perfect environment for the lasers, because a space platform can engage, for example, a spy satellite or ground targets with the use of HPL; however, the reverse is true (Brasil, 2006). An example of this, according to Dunn (2005), occurred in 1984, when the Union of Soviet Socialist Republics (USSR) used a Ground Based HPL (GBL) against the U.S.' space shuttle, the Challenger, causing malfunctioning of the onboard equipment and stress on the crew.

\section{DEFENSIVE OPERATIONS}

In defensive operations, the HPL can provide self-defense measures for the air, land and naval platforms, as well as protect other platforms without protective systems. Lasers can be used against missiles, aircraft, satellites, UAV, bombs, artillery projectiles, rockets or mortars, neutralizing these threats before they reach their targets.

The first use of the laser for self-defense purposes occurred in 1973, when the USAF Weapons Laboratory (AFWL) hit a drone flying at $200 \mathrm{Kts}$, using a $\mathrm{CO}_{2}$ laser based on ground. In 1983, the same laboratory carried out tests against the AIM-9B Sidewinder missile, which was kept at 2000 Kts (Dunn, 2005).

In air operations, lasers incorporated into self-defense systems are responsible for increasing the survivability of many aerial platforms, particularly the subsonic platforms, such as the E-8 Joint STARS (Joint Surveillance Target Attack Radar System), the E-3 Sentry AWACS (Airborne Warning and Control System) and the ABL B-747 (Federation of American Scientists, 2013). These aircrafts are considered strategic targets in OT and are called High Value Airborne Asset (HVAA). Furthermore, the use of laser systems for self-defense in attack aircraft against SAM and AAM missiles reduces the suppression of enemy air defense workload, making the OT less widespread. In other words, an air campaign can begin with interdiction actions before obtaining air superiority stage, reaching the enemy gravity centers in a shorter time, which also will result in lower costs and less collateral damage.

In land operations, HPL can increase the survival of the troops, as well as enable greater land mobility. These systems can be mounted on tanks to intercept missiles, artillery shells, rockets and mortars, increasing the OT self-defense. An example, previously mentioned in this paper, is the THEL type system, which has the ability to destroy rockets, mortars and other artillery ballistic projectiles.

Several features that benefit the air defense and land operations also provide naval defense operations, increasing the fleet flexibility. For instance, lasers can provide an effective shield from ballistic or cruise missiles, allowing the permanence of warships greater proximity to the enemy coastline within the firing range of tactical missiles. One of the biggest threats of naval forces is the Supersonic Sea-Skimming Missile Antiship (ASCM) (Federation of American Scientists, 2013), which may be undetected until seconds before impact. In this case, HPL can offer a high rate of engagement of these threats.

Strategically, as well as in offensive space operations with HPL, defensive operations by satellite based lasers are able to monitor and defend large areas on Earth's surface against ballistic missile much faster than land protection systems, because this type of threat can be engaged shortly after launch and at higher altitudes.

\section{CONCLUSIONS}

The presentation of the operational implications of HPL weapons is the first step to aware for operational and scientific community of the evolution in this area and it is used in order to alert the authorities about the military importance given on the nations with high technologies developed.

Initially, this paper described the capacity of HPL, as well as the progress in its integration with air, land and naval platforms. It also was presented the attractive costs and benefits ratio. Thereafter, it was explained the necessity of operational concepts development on Armed Forces, in order to guide appropriate manufacturing laser weapons, highlighting the HPL capabilities and limitations. Finally, it was presented an overview of offensive and defensive operations enabled by use of HPL weapons. 
Therefore, according to the evidence of operational applications with laser weapons systems in many conflict situations, a new age in military and civilian community is possible, where postgraduate programs as the PPGAO can guide the development of concise operational concepts, joining the scientific knowledge with operative know-how, since one complements the other and vice-versa.

\section{REFERENCES}

Brasil, Ministério da Defesa do. Comando da Aeronáutica, 2006 , "Comando-Geral de Operações Aéreas. NSCA 500-1: Sistema de Guerra Eletrônica da Aeronáutica”, Brasília: COMGAR.

Dunn, R.J., 2005, "Operational Implications of Laser Weapons", Retrieved in June 22, 2013, from http://www. northropgrumman.com/AboutUs/ AnalysisCenter/Documents/dfs/Operational_Implicationsof_La.pdf.

Federation of American Scientists, 2013, "Website about science and technology in the fields of biosafety, technology analysis and strategic security", Retrieved in June 20, 2013, from http://www.fas.org/.

Hecht, J., 2010, "A Short History of Laser Development", Optical Engineering, Vol. 49, No 9. Retrieved in June 25, 2013, from http:// www.if.ufrgs.br/ jgallas/pub/FisAtoMol/hecht_short_-history_of_ laser_development_OE2010.pdf.

Monteiro, E.C., Geraldo, J.A. and Oliveira, J.E.B., 1994, "Fotônica e Optoeletrônica: Pesquisas Desenvolvidas na Divisão de Engenharia Eletrônica do ITA", Revista ITA Engenharia, Vol. 1, No 1, pp. 13-16.
Northrop Grumman, 2013, "DIRCM, Directed Infrared Countermeasures", Retrieved in June 24, 2013, from http:// www. northropgrumman.com/Capabilities/DIRCM/Pages/ default.aspx.

Oliveira, J.E.B., 2002, "Ciência, Tecnologia e Inovação em Áreas de Interesse da Defesa", Retrieved in June 22, 2013, from https:// www. defesa.gov.br/arquivos/pdf/ciencia_tecnologia/palestras/ ctidefesa.pdf.

Poder Aéreo, 2009, "Pod Litening no A-1 da FAB na Operação Laçador", Retrieved in June 25, 2013, from http://www. aereo.jor.br /2009/11/19/pod-litening-no-a-1-da-fab-na-operacao-lacador/.

Popular Mechanics Journal, 2009, "The Navy's New 100 kW laser weapons", Retrieved in June 25, 2013, from http://www. popularmechanics.com/technology/gadgets/4321422.

Thomas Jefferson Laboratory, 2013, "Free Electron Lasers", Retrieved in June 21, 2013, from https://www.jlab.org/FEL/. 